\title{
reviews
}

When Maurice Clavelin's Essay on the Origins and Formation of Classical Mechanics first appeared in French in 1968 , it was widely recognised as a work of much originality, and nothing published since that first appearance has made very serious inroads into his main conclusions. The Essay is a long and intensive study of "a transition from one conceptional framework to another, the replacement of one explanatory ideal with another and an unprecedented fusion of reason and reality", and $M$. Clavelin argues that to evaluate the scope of the revolution "we must try to view Galileo's work from within". He professes to make no systematic reconstruction of the intellectual and social context in which Galilean science evolved, and yet, overlooking these modest protestations, the reader will have no difficulty in extracting just such materials. The book begins with the Aristotelian doctrine of motion--the intrinsic analysis of local motion, the cosmological frame without which local motion (for Aristotle) was inconceivable, and the descriptive analysis of local motion (the classification of it, the evaluation of its magnitude, and resistive force). By emphasising the coherence of the Aristotelian theory, and the interrelations of the cosmos and local motion, M. Clavelin explain how-far from being the heap of inanities some popular histories would have us believe - it could be questioned and extensively qualified by great minds, without collapsing into a pile of rubble. And if that is important to an understanding of Galileo, then the traditions of the 14th century schools of Oxford and Paris was even more so.

In that connection, Galileo for long misled his commentators by lavishing praise on Archimedes at the expense of Aristotle. Of the fact that Galileo's technical language owed much to mediaeval precursors there is no doubt; but how extensive was his debt to them? Like them, Galileo at first tried to relate the increase in speed of a falling body to its spatial position rather than to time. (After all, according to Aristotle, motion depended on position.) The mediaeval doctrines were an established part of the teaching he had at Pisa between 1583 and 1586. In his Juvenilia Galileo reveals himself as in many respects an Aristotelian, and his early Treatise on the Latitude of Forms includes many allusions to the Mertonians and Parisians. Simultan-

\section{Focusing on Galileo}

\author{
J. D. North
}

The Natural Philosophy of Galileo: Essays of the Origins and Formation of Classical Mechanics. By M. Clavelin. Pp. xiii + 498. (MIT Press: Cambridge, Massachusetts, and London, 1974).\$25.00. Two New Sciences. Including Centers of Gravity and Force of Percussion. By Galileo Galilei. Table introduction and notes by Stillman Drake. Pp. xxxix + 323. (The University of Wisconsin Press: Madison, Wisconsin, 1974.) $\$ 14.00$ cloth; $\$ 5.00$ paper.

eously with these early writings, however, Galileo was reading Euclid, Archimedes (especially on hydrostatics), and Tartaglia (on projectiles). These works convinced him of the need to replace the textual criticism and qualitative dialectic of the philosophers with a direct and mathematical method. The first taste of the great power of the essentially geometrical method for the analysis of physical problems was evident in the early works De motu and Mecaniche. For the greater Dialogue and Discourses, in which the method was exploited far more fully, the world had to wait some decades, and this because from 1602 until his death in 1642 Galileo found a need to link Copernicanism with the mathematical science of the motion of heavy bodies. Into this period, of course, came the telescopic discoveries which so distinguished the Galilean outlook. M. Clavelin reminds us how important was the cosmological component in thought about motion, before Newton's time. Galileo, for instance, was never to abandon the view "that circular motion alone had an actual and real power of indefinite self-conversation". Unlike his precursors, we are told, Galileo was able to treat local motion as a state rather than as a process, and Copernicanism indeed set Galileo the problem of justifying the idea of an orderly world in which motion, not rest, is the normal state of the Earth. His analysis of the Earth's diurnal motion (as in the Second Day of the Dialogue) led him to create some of the most significant of his mechanical concepts-such as the idea of an inertial system, the principle of the conservation of uniform motion, and the principle of the composition of motions. M. Clavelin explains all that beautifully, and at length, steering a middle course between the positivism of Duhem and the Platonism of Koyré. $\mathrm{He}$ contrasts the contents of the Dialogue with the corresponding parts of the Discourses, and at the same time emphasises a "lack of cohesion" in Galileo's mechanical ideas which denied him the opportunity of discussing properly the planetary motions in mechanical terms, and which indeed made impossible the treatment of weight as a force.

Before Professor Drake's work, the last important English translation of the Discourses (1638) was prepared by Henry Crew and Alfonso de Salvio in 1914 under the title Dialogues Concerning Two New Sciences. Earlier English translations had been published in 1665 and 1730. In the introduction to Drake's new translation, reasons are given for thinking a new version desirable. The changes are not such as to strike the casual reader as very significant, but it is the very fact that they are spelt out at length which gives the new version its value. Take the (Italian) noun mobile, for instance, signifying a tangible and heavy moving object near the Earth's surface. This is now rendered by the English 'moveable', in contradistinction to the adjective 'movable'. Crew and De Salvio translated mobile to mean 'particle', to which objection is now made on the somewhat curious grounds that "the modern physical particle is essentially devoid of weight". As another example, Professor Drake dislikes the introduction of the mediaeval concept of "mean speed" into the statement of Galileo's basic first theorum on accelerated motion, in place of "onehalf the final speed". Whatever the reader's feelings over these subtleties, it is undeniable that the new version must now replace the others. It includes original Galileo works which were published posthumously in the form of a dialogue on the force of percussion (intended for the 1638 edition, but not finished to Galileo's satisfaction), and Galileo's work on centres of gravity. Professor Drake, whose reputation as a Galileo scholar is well known, adds some useful notes, as well as a bibliography of the principal editions and translations of the Two New Sciences. The new version, like the original Leyden (Elzevirs) edition, is very attractively designed and printed, and not unduly expensive. 